\title{
Yuan Zhi Xi Li Si son of a LAN, but could not speak out -- Interpretation of "Jiu Ge Xiang Qu poems" Mrs.
}

\author{
Wu Changlin 1,a, Tang Jichong 2, b* \\ ${ }^{1}$ College of Humanities and Social Sciences, East China Jiaotong University, Jiangxi, Nanchang \\ ${ }^{2}$ College of Humanities and Social Sciences, East China Jiaotong University, Jiangxi, Nanchang \\ 619822948@qq.com \\ *Tang Jichong
}

Keywords: Mrs. Xiang; content; structure art; emotional art

\begin{abstract}
Madam Xiang" as "companion" Xiangjun, this article from the perspective of Madam Xiang Xiangjun missing write poetry, dark counterpart, complement each other, constitute a harmonious realm. Study on the "Hunan madam" focused on analytical Hunan's image and identity, you can interpret from "structural art and emotion art" the lady of Hunan, Hunan and reveal Xiangjun love between each other, always to show Qu Yuan the love of the motherland, the great personality of political ideals and the pursuit of independence don't move.
\end{abstract}

\section{Introduction}

"Madam Xiang" and "Chu Tzu" as one of the eleven poems, is offering Xiangshui goddess of poetry, "and" Xiangjun is a companion.The interpretation of "Xiang" the lady must be filled with gas from the understanding of the Chu culture, "Xiang" Lady written mainly hero Xiangjun and Xiang Furen date but not see, reflects the primitive worship of natural gods is a kind of ideology and the concept of "God love". It is to write to miss Xiangjun madam Xiang tone, poetry, light corresponding to complement each other, constitute a harmonious realm, depict God at the Hunan Mrs. Chi Xiangjun, pray that not to hope, and not see melancholy mood. Although the poem "Madam Xiang", but the protagonist of the poem is xiangjun. The theme of the poem is mainly about love die, who missed the rendezvous, when people do not come to work always as a clue, expressed deep hatred towards each other in the void, but the love between each other is the same as.

\section{Interpretation of the content of Mrs. Xiang}

\subsection{The interpretation of the background of "myth and legend" of Madame Xiang}

"Nine Songs" is a general term for his eleven works. "Nine" is generic, non real, "Nine" is the ancient name of chapter. "Madam Xiang" for "Nine Songs" in an article. Wang Yi "chucizhangju": "Xi Chu Nan Ying City, yuan, Hunan, the customs and the good temple, the temple will be a song inspired by music gods. Qu Yuan in exile, to hide its domain, with sorrowful poison, but Yu boiling. See the worldling sacrificial rites, dance and music, as the "Nine Songs". Chen God of the king, see oneself Yuanjie, support to satirisation." 2

Some people think that $\mathrm{Qu}$ Yuan is based on the processing of folk sacrificial songs and $\mathrm{Zhu} \mathrm{Xi}$, "Chu Ci variorums" cloud: "the word is quite Jing vulgar, vulgar, and the ghost between yin and yang. Or not a dissolute miscellaneous. The original is in exile, see and sense, so is more to the Thai word, what. For one thing, the heart of God, to send my patriotic attachment not forget. Is he is not too close if the jade Yan, and a gentleman for you." According to Qu Yuan, the "Nine Songs" is Qu Yuan in exile in Jiangnan, creation based on a folk ritual songs for folk ritual songs. "Nine Xiang lady" is now generally write this poem Xiangjun and Xiang Furen date, wait a long time, but still have not seen the arrival of Madam Xiang melancholy, is used to worship God Xiangshui songs. As a sacrifice of Chu people's gods, "Madam Xiang" reflects a kind of ideology of primitive people worship of natural gods, Chu folk art, has a strong religious atmosphere, the altar is actually the "drama" or "literary". 


\subsection{The interpretation of the theme of "love between man and God" in Madame Xiang}

"Xiang" lady with female voices or offering play role as a "Companion to Xiangjun," Xiangjun, that is a pair of Hunan and Mrs. Xiangjun spouse, such as less contemporary and big powers is one of the works by God, the sustenance of the beautiful world of love, God and people have feelings, have joy also have sorrow, but also reflects the harmony between people and nature of chu.

Although the poem "Madam Xiang", but the protagonist of the poem is xiangjun. Works with waiting for Madame Xiang Xiangjun, but madam Xiang is not always as a clue, this Xiangjun said sorry, but in any case of Hunan Xiangjun's love is constant. This paper describes a love of life, missed the rendezvous die and story. If the two first offering Divine Comedy together, "then" and "Madam Xiang" Xiangjun plot closely, "Xiang" is written by Mrs. in Hunan do not keep the appointment of Mrs. Long xiangjun. Therefore, when arrived at the rendezvous Xiangjun, natural and not meet sweetheart.

\section{The interpretation of the structural art of Madame Xiang}

\subsection{Madam Xiang, verse 1}

"Xi Bei Zhu's drop, so how come to worry about. Come autumn curl, wave Xi Dongting leaves. On white Fan Xi Cheng Wang, and every night, Zhang xi. Where Xi Ping Cui bird, what is wood Xi zeng. Yuan Zhi Xi Li Si son of a LAN, but could not speak out. The shortage of water, and come from afar, the concept of flow slowly."

Mei Juan autumn breeze brought bursts of coolness, is a symbol of the protagonist's inner bit melancholy; the waves of the Dongting Lake, is a symbol of the hero does not calm the mood; have fallen leaves, symbolizing the heart master just slowly sinking. In the face of the vast Dongting Lake Yanbo, feel boundless boundless Xiangjun mind. This feeling has all blend into one harmonious whole.

In haste, Xiangjun boarded the long white Fan Highlands, to look farther. He clings to the thought that Mrs. Xiang is coming, and Mrs Xiang is walking towards him. The poet here he added two sentences, to illustrate that backfired, and not to call Xiangjun, ask not. Then, a poet and further description of Xiangjun images.

Just like the Yuanshui River and Lishui Zhi grass orchid, andplayed madam Xiang emotional tide, is the impact of Xiangjun heart bursts. The difference is, Yuanshui River and Lishui Zhi grass orchid to natural normal exudes their fragrance. But madam Xiang did not come, that is in the middle of the blazing Xiangjun and sweet emotion there is no place to resolve. When to see a distant and indistinct scene Xiangjun, only to see it day and night, always a never-ending stream of long Dongting lake. All of this is now enrapt Xiangjun mood portrayal, is a symbol of the total Xiangjun also wipe desolate melancholy. The word "Southern Tang Emperor Li Yu" "q-how can worry about? Like a river flows to the East, the source for this almost cover! 3

\subsection{Mrs. Xiang, one poem second paragraph}

Where the food court in the "Mi Xi? What is the origin of water Jiao Xi? Chi Ma Xi Jiang Gao Chao Ji Xi Xi Xi, Shi. When I hear the wind, I call it. Build a room Xi water, Qi Xi Wu Xi Hegai; wall purple altar, sowing Gilpin hall into Gui Xi Xi; Dong Lan Liao, Xinyi Mei Xi Xi is a useless pharmacy; Ficus pumila curtain, to Mian Wai Xi both Zhang Xi; Baiyu Town, Shi Lan Shu Xi is Fang Zhi Xi; a Dutch house. Liao Xi du. He Xi real Baicao court, Jian Fang Xin Xi Wu door. Nine Yi Bin Xi and Ying, Ling Xi to clouds." 4.

Why are the milu deer foraging in the yard? Why did the Dragon wander along the water's edge? In the early morning, I beat the horse on the river bank, and in the evening I crossed to the west of the river. I heard that Mrs. Xiang is calling me. I will drive with her. I want to build my house in the middle of the water, and put the lotus leaves on the roof. Sun deck wall ah Zibei grass paved court altar. I used to decorate the hall walls with pimenta. Guangxi wood beams ah Mulan truss rafter, Xinyi installed lintel decorated bedroom Angelica ah. Weaving made the curtain opened on Bili ah, our grass hangings have a piece of. With white jade ah, made town seats, everywhere furnishings, 
Shi Lan ah, an aroma. In charge covered Zhi grass house, with his winding quartet. Collect all kinds of flowers ah covered courtyard, built both fragrant and beautiful porch. Nine Yi mountain gods are welcome to Hunan lady, they hold the crowd like the cloud cluster.

This section begins with a series of two poets, metaphor: "what food court in MI Xi, where Xi water mosquito born", this should be in the elk mountains, now why went to people in the courtyard to seek food; the dragon should be hidden in the abyss, now why run to. In front of them with the "bird where extraction Xi reservoir, with what is on the Xi wood" meaning the two sentences of the same, is the protagonist in extremely sad mood under the gun trance illusion, with inconsistent to show the subjective intention and objective facts xiangjun. "For extreme despair, fantasy naturally becomes a form of self relief. Freud once said that fantasy springs from the hearts of those whose desires are not fulfilled.

\section{The interpretation of emotional art of Madame Xiang}

\subsection{Double line parallel extension}

This poem is described by Xiangjun and Xiang Furen date, wait a long time, but not the process of Madam Xiang coming, lyrical narrative with the emotional ups and downs of synchronous performance. According to the development of events, can be roughly divided into three layers: the first layer, from the beginning to the "Jiao Xi - what is the water", the occurrence and development of the event, showing reverence and melancholy Xiangjun second layers; from "toward the Xi Jiang Gao ride" to "the spirit of the clouds to Xi", write Xiangjun illusion suddenly he heard in Hunan lady called him, he died, Kai Teng drive built room in the water, hope and sharing the good life of Madam Xiang showed very excited, Xiangjun joy; third, from the end of "Yu Mei Xi River to donate," wrote Xiangjun from the illusion back to reality after the anger, disappointment, regret, and initiation complex the mood of hope. Qu Yuan, through narrative, lyrical, double parallel, synchronous extension.

\subsection{Landscape scenes.}

"For example, come autumn curl wrote" in the poem, Dongting wave Xi leaves "," Miao Miao sees "," reason to worry ". What we see before us is why we give it to us because of what we see. We want to see the "drop's Xi Bei Zhu", to see the results of the subjective desire exists in the opposite direction and is associated with the autumn leaves, autumn autumn scene. A poet can write in front of king heart, all kinds of sensory information in cortical neurons of the brain shift by synaptic communication, to establish contact with the emotional heart, it works in the "king of all words are love language" (Wang Guowei "human words"). Hu Yinglin "poem" said "come autumn curl, wave $\mathrm{Xi}$ Dongting leaves" and "lackaday describe autumn autumn for gas", it is a short description attentively, the progenitor of autumn. The six generation of Tang poetry, since the person doesn't. After Du Fu's "boundless Xiao Xiao Lamu, endless rolling to the Yangtze River" ("climb"), Li Yi "q-how can worry about, it is a river flows to the East" ("Poppy"), Li Qingzhao "huazipiaoling artesian water" ("yijianmei") the wording of this poem class, lyrical can also be called a generalization of synaesthesia.

\section{Conclusion}

"Madam Xiang" is a tragedy, because Xiangjun madam Xiang missed each other and date time, and may not meet. But you can also say "Madam Xiang" is a comedy, and although not meet Mrs. Xiangjun Hunan, but the love between each other is not reduced, but it is even more deep. If two people meet, all misunderstandings and troubles vanish, and what awaits them is happiness and joy. "Xiang" Lady poem strange idea, "gorgeous, rich in Active Romanticism, Qu Yuan borrow not wait until madam Xiang Xiangjun, which refers to that they can't reuse the. The use of a variety of works of art expression, enhance the artistic appeal, although the hot $\mathrm{Qu}$ Yuan beautiful love hidden in religious ceremonies, but its powerful life force, the release of positive energy infinite, let our brave, for the pursuit of the ideal and great love. 


\section{References}

[1] Hong Xingzu, filling notes in songs of the Tang Dynasty,Beijing, Zhonghua Book Company, pp. 107, 1893.

[2] Li Wang, brief introduction to meeting pleasure, Shanghai, Shanghai Ancient Books Press, pp. $215,1891$.

[3] Zhu Xi, biography of poetry, Shanghai, Shanghai Ancient Books Press, pp. 186-187, 1980.

[4] Liu Yongji, "Qu Fuyin note detailed", Shanghai, Shanghai Classics Publishing House, pp. 177, 1983.

[5] Hu Yunzhen, Selections of Song Ci, Shanghai, Shanghai Ancient Books Press, pp. 207, 1982.

[6] Jiang Liangfu, Qu Yuan and Chu Ci, Anhui: Hefei: Anhui Education Press, 1996 edition, pp. 257.

[7] Zhou Jianzhong, Study on "Chu Ci", Beijing: the Commercial Press, pp. 120-121, 2007. 